\title{
Exposition des ymages des figures qui sunt: discursos sobre imagens no Ocidente Medieval
}

\author{
Exposition des ymages des figures qui sunt: discourses about images in \\ Medieval Occident
}

Maria Cristina Correia Leandro Pereira ${ }^{1}$

RESUMO

Ao contrário do que indica a famosa - e questionável - fórmula "Bíblia dos iletrados", os discursos medievais sobre as imagens iam bem além de apenas destacar sua função didática. Neste artigo, apresentamos uma mostra dessa diversidade, analisando uma série de textos medievais acerca de imagens, que dividimos em cinco grandes categorias (não excludentes e por vezes complementares). 0 primeiro grupo, o mais numeroso, é o dos discursos teóricos sobre imagens, envolvendo questões teológicas. Em seguida, ainda que fundado em argumentos de ordem teológica, um segundo grupo corresponde àqueles textos em que se busca intervir na prática das imagens por meio de proposições normativas. Decorrente dos tipos anteriores é o terceiro grupo, o dos discursos que tratam da recepção das imagens, das reações frente a elas. Um quarto grupo são os escritos que mencionam os produtores de imagens: tanto os documentos de tipo prático quanto os comentários com juízos de valor a respeito do trabalho daqueles. E, por fim, estão os textos que trazem descrições, desde os que seguem de perto o gênero retórico da ekphrasis àqueles que descrevem a materialidade das imagens.

Palavras-chave: Imagem. Discursos. Ocidente Medieval. Artistas. Textos.

ABSTRACT

Contrary to what indicates the famous - and questionable - formula "Bible des illetrés", the medieval discourses on images went well beyond just highlighting its didactic function. In this article, we present a sample of this diversity, analyzing a number of medieval texts dealing with images, which we have divided into five broad categories (not mutually exclusive: on the contrary, sometimes complementary). The first and most numerous are the theoretical discourses on images involving theological questions. Then, still

${ }^{1}$ Professora Doutora de História Medieval no Departamento de História da Faculdade de Filosofia e Ciências Huanas da Universida de de São Paulo. 
based on arguments of theological order, a second group corresponds to those texts that seek to intervene in the practice of images through normative propositions. As a result from the previous two types is the third group: the speeches dealing with the reception of images and the reactions they cause. A fourth group are the writings that mention the producers of images: both practical documents and those that express value judgments about their Works. And finally, there are texts that describe the images, both their iconographic content and their materiality.

Keyword: Images. Discourses. Medieval Occident. Artists. Texts.

"No começo era o Verbo. [...] E o Verbo se fez carne", assim diz o Evangelho de João, em uma das passagens mais importantes para a história do cristianismo (Jo 1, 1; 14). Feito carne, depois de um longo e complexo processo, e muitos debates, o Verbo se fez também imagem - e, portanto, pedra, madeira, ouro, prata, pedras preciosas, marfim, esmalte, pigmentos. O Verbo, feito carne, imagem e matéria, fez-se ainda verbo, pelas mãos de escritores medievais e pós-medievais.

Essa pequena narrativa histórico-mitológica trata do objeto deste trabalho: esse verbo - com v minúsculo - sobre a imagem. Ou, dito de forma mais precisa, os discursos medievais a respeito das imagens. A opção pelo uso deste plural, discursos, é fundamental. Um dos objetivos aqui pretendidos é por em xeque a ideia de que só teria existido um tipo de discurso medieval: aquele que atribui uma função didática às imagens (e, consequentemente, de que só existiria um tipo de imagem). Tal visão está sintetizada na tão repetida fórmula "Bíblia dos iletrados", que tem em Émile Mâle um de seus criadores², a partir de uma leitura com certo grau de ingenuidade da famosa carta do papa Gregório Magno ao bispo Sereno de Marselha no século VI (GREGORIVS MAGNVS, Epistola ad Serenum Massiliensem episcopum XI, 13, 1895, col. 1128-1130). No entanto, esta carta, em que o papa aconselhava o bispo a não mais destruir imagens, uma vez que, entre outras utilidades, elas poderiam servir de leitura para os que não sabiam ler, não sintetiza o conjunto de discursos medievais sobre imagens, apesar de todo o prestígio do autor. Assim, ela não pode ser investida da aura de autoridade e exclusividade como fez o discurso tradicional dos historiadores e historiadores da arte ${ }^{3}$.

Tratemos aqui de diferentes tipos de discursos medievais sobre as imagens, mostrando a riqueza dessa produção. Podemos dividi-los em cinco grandes grupos, lembrando, porém, que se trata de um recurso didático, uma tipologia artificial, posto que os contatos entre eles são importantes, e muitos dos discursos se encaixariam em mais de um dos tipos aqui definidos. O primeiro, o mais numeroso, é o dos discursos teóricos sobre imagens, envolvendo questões teológicas: grosso modo, respondendo a questões como "o que são imagens" e "para que elas servem". Em seguida, ainda que fundado em argumentos de ordem teológica, um segundo grupo corresponde àqueles textos em que se busca intervir na prática das imagens por meio de proposições normativas que próibem ou autorizam determinados tipos e usos de imagens. Decorrente dos tipos anteriores é o terceiro grupo, o dos discursos que tratam da recepção das imagens, das reações frente a elas - em geral, com intenções moralizantes. Um quarto grupo são os escritos que

\footnotetext{
${ }^{2}$ Assim ele abre uma de suas obras mais conhecidas: "A Idade Média concebeu a arte como um ensinamento. Tudo que era útil ao homem conhecer, a história do mundo desde sua criação, os dogmas da religião, os exemplos dos santos, a hierarquia das virtudes, a variedade das ciências, das artes e dos ofícios, era-lhe ensinado pelos vitrais da igreja ou pelas estátuas do portal" (MÂLE, 1910, p. 6). Salvo indicação contrária, todas as traduções para o português apresentadas neste artigo são da autora.

3 Ver a esse respeito, entre outros: Duggan (1989, p. 227-251) e Chazelle (1990, p. 138-153).
} 
mencionam os produtores de imagens: tanto os documentos de tipo prático, como os contratos de prestação de serviços, quanto os comentários com juízo de valor a respeito do trabalho realizado. E, por fim, estão os textos que tratam das próprias obras, em geral de tipo descritivo, abarcando desde os que seguem de perto o gênero retórico da ekphrasis às inscrições nas próprias imagens.

\section{Dos discursos teóricos sobre as imagens}

No primeiro grande grupo encontra-se a grande maioria dos textos medievais sobre imagens: os que têm um cunho teológico - e que possuem, por isso mesmo, um caráter generalizante, sem referir-se a nenhuma imagem específica. As posições que eles defendem vão de favoráveis a contrárias às imagens, chegando ao ponto extremo da iconoclastia, em alguns momentos precisos, como em Bizâncio nos séculos VIII e IX. Duas são as fontes básicas: as Escrituras e a tradição greco-romana, recortadas e montadas de acordo com os diversos interesses. Ao Segundo Mandamento mosaico, por exemplo, que diz "Não farás para ti imagem de escultura, nem alguma semelhança do que há em cima nos céus, nem em baixo na terra, nem nas águas debaixo da terra" (Ex 20, 4), podia ser contraposta a Criação do Homem, "E disse Deus: Façamos o homem à nossa imagem, conforme a nossa semelhança" $(G n$ 1, 26), além da própria Encarnação do Cristo; a acusações de idolatria podia ser contraposta a serpente de bronze ( $\mathrm{Nm} \mathrm{21,8-9)}$ e os querubins da arca da aliança (Ex 18-20); à impossibilidade de visualizar a divindade podia ser contraposta a ideia de transitus pela imagem ao protótipo; e assim por diante.

Como se trata de um amplo dossiê, impossivel de ser esgotado nos limites desse artigo, selecionamos os casos que serão mais frequentemente retomados ao longo da Idade Média. Neles, duas questões são fundamentais: a relação entre texto e imagem e a relação entre imagem e protótipo - questões estas, aliás, que não são importantes apenas para o cristianismo medieval, pois elas estão, de alguma forma, no cerne das discussões sobre a própria ideia de imagem, sejam elas na Antiguidade, sejam na contemporaneidade; no mundo da religião ou na Teoria da Arte.

Retomando a ideia sintetizada na expressão horaciana (Ars poetica, 361, HORACE, 1926, p. 480) "ut pictura poesis" ("assim na pintura como na poesia"), grande parte dos autores medievais sustentavam que as imagens serviriam de substitutas aos textos, sendo portanto especialmente adequadas aos iletrados. A autoridade maior é, como dissemos, o papa Gregório Magno, que assim escreve ao bispo Sereno:

Uma coisa, em efeito, é adorar uma pintura, e outra, é aprender por uma cena representada em pintura o que se deve adorar. Porque o que a escrita [scriptura] proporciona às pessoas que leem, a pintura oferece aos iletrados [idiotia] que a 
olham, porque esses ignorantes veem aí o que devem fazer; aqueles que não conhecem as letras leem aí, de modo que a pintura desempenha o papel da leitura, sobretudo entre os pagãos [gentibus] (GREGORIVS MAGNVS, 1895, col. 1128).

Embora estas ideias fossem ter vida longa nos séculos seguintes, muitos são os argumentos que poderiam ser usados contra seu uso abusivo pelos modernos historiadores da arte: desde o fato de que se trata de uma carta específica, e não um dogma, à observação de que ele só fala de pinturas narrativas.

Além disso, não se trata de uma visão monolítica por parte dos autores eclesiásticos. Um exemplo bastante interessante, embora anterior a Gregório e menos famoso, é um dos poemas do bispo Paulino de Nola, do início do século $\mathrm{V}$ :

E é por isto que pensamos ser útil avivar todas as casas de Felix com pinturas de temas sagrados, na esperança de que elas estimulariam o interesse dos rústicos por sua aparência atrativa, já que os desenhos são pintados em várias cores. Sobre elas há inscrições explanatórias, a palavra escrita revelando as que foram desenhadas pela mão do pintor. Assim [...] os camponeses as apontam e leem uns para os outros os temas pintados [...] (PAULIN OF NOLA, 1975, p. 291).

Apesar de a velha equiparação entre texto e imagem estar presente nessa passagem, é a imagem, de certa forma, que está em destaque. É o texto que serve de apoio para a compreensão dela. Há, portanto, uma inversão da ideia do papa. Mais tarde, isso teria um paralelo nas próprias imagens: naquelas que apresentam inscrições - tanto em miniaturas de manuscritos quanto em pinturas murais, esculturas etc. Mas retornaremos a esse ponto mais adiante.

Voltando ao papa, é importante perceber que ele não se limita a indicar essa função didática e memorial na carta. Ele defende outra importante utilização: "a partir da visão do evento figurado, eles [os fiéis] deveriam alcançar o ardor da compunção e prosternar-se em adoração da Santíssima Trindade" (GREGORIVS MAGNVS, Epistola ad Serenum Massiliensem episcopum XI, 13, 1895, col. 1129). Assim, pois, as imagens poderiam também ter uma função devocional, ao comoverem o espectador - sempre com a ressalva de que não deveriam ser adoradas, pois a adoração estaria reservada unicamente ao protótipo.

E é esse o segundo ponto que mencionamos antes: a relação entre a imagem e o protótipo. Se para Platão ${ }^{4}$ e, mais adiante, Santo Agostinho5, a imagem nunca seria da ordem da verdade, para muitos autores

\footnotetext{
4 "Longe então da verdade está a arte da imitação. E se isso tudo produz, é, ao que parece, porque apreende apenas um pouco de cada coisa, e esse pouco é um simulacro [eidolon]" (PLATÃO, 2001, p. 455).

5 Como diz o bispo de Hipona nos Solilóquios: "Uma coisa é querer ser falso, e outra coisa não poder ser verdadeiro., [como] as obras dos pintores e escultores [...]" (SANTO AGOSTINHO, 1998, p. 78).
} 
medievais a imagem poderia servir de caminho à verdade do protótipo, como definia o Concílio de Niceia II, em 787 (lembrando que no mundo bizantino havia uma preocupação de ordem normativa em relação às imagens - mais precisamente aos ícones - bastante mais importante do que no cristianismo latino): "a honra concedida ao ícone atinge o protótipo e aquele que se prosterna diante do ícone se prosterna diante da hipóstase daquele que está inscrito nele" (HOROS... 1987, p. 33).

A ideia do transitus pela imagem também teria vida longa no Ocidente medieval, como podemos ler nas portas de bronze dourado que o abade Suger mandara fazer para a fachada oeste da basílica de Saint Denis, consagrada em 1140:

Quem quer que sejas, se pretendes exaltar a glória destas portas, não te maravilhes pelo ouro, nem pelo custo, mas sim pelo trabalho da obra. Resplandece a nobre obra, mas a obra que nobremente resplandece clarifica as mentes, para que se encaminhem pelas luzes para a verdadeira luz, onde Cristo é a verdadeira porta. Como se entra neste mundo, a porta dourada o determina. A mente, ofuscada, se eleva à verdade pelas coisas materiais e, depois de ver essa luz, ressurge da antiga submersão (SUGER, 1979, p. 46-48) .

Suger não está propondo algo novo, ele retoma ideias neoplatônicas do Pseudo-Dionísio (século V) ${ }^{7}$, traduzido no período carolíngio por João Escoto Erígena. Mas a grande diferença é que, além de dar uma visibilidade e uma materialidade ainda maior a essas ideias, ele também as põe em prática, com as obras que leva a cabo na basílica, com vasto emprego de ouro e pedras preciosas em sua ornamentação. O "trabalho da obra" que Suger faz conjuga o brilho da matéria (transformada, pois, em luz) com a própria função do objeto (a porta, mas também todo o portal) que ela reveste, além da iconografia nele presente: o Cristo do Juízo Final, no tímpano acima da porta. "Assim no texto como na imagem e na matéria": a expressão horaciana encontra corpo em Suger, que ainda se faz representar na imagem ajoelhado aos pés do Cristo, com as mãos e a cabeça tocando sua mandorla, acima dos mortos que ressuscitam.

\section{Dos discursos práticos}

\footnotetext{
${ }^{6}$ A porta atual não é a original, que terminou de ser destruída durante a Revolução Francesa, mas fruto de uma restauração do século XIX. Ver, a esse respeito, entre outros: Blum e Crosby (1973, p. 209-266).

7 Ver, a esse respeito, entre outros: Panofsky (1979, p. 19-25); Gerson (1986, p. 186).
} 
Não existiu na Europa medieval ocidental uma preocupação por parte da Igreja em normatizar de fato o uso de imagens ou, menos ainda, seu conteúdo iconográfico. Mesmo após o Concílio de Trento, a preocupação será mais com o decoro - ou seja, com a adequação das imagens ao lugar e ao objetivo para os quais foram feitas (e não, como se pensa hoje, que indecorosas seriam apenas as imagens de nus, por exemplo - nesse caso, a imagem do Cristo seria a mais indecente de todas) - do que com seu conteúdo. Encontramos somente algumas indicações, muitas vezes de caráter geral, como é o caso de um texto bastante antigo, do final do século II, o Pedagogo, de Clemente de Alexandria - que é também uma das primeiras referências textuais que possuímos sobre imagens cristãs:

E deixe ser nossos selos uma pomba ou um peixe, ou um navio deslizando pelo vento [...]. Mas nós não devemos desenhar imagens dos ídolos, nós, que renunciamos a nos vincular a eles; nem espada, nem arco, já que nós buscamos a paz; nem taças, por sermos comedidos (CLEMENTE DE ALEXANDRÍA, 2009, p. 598).

A justificativa didático-moralizante está explicitada, com indicações não só de como devem ser (e não ser) as imagens, mas também de como devem ser os cristãos: comedidos, pacíficos. Há, pois, uma relação direta entre as imagens e o que elas representam, fazendo com que elas sirvam de signos de identificação (e de contraidentificação). Como observado, trata-se de uma questão de decoro, de decus.

Existem, certamente, textos mais detalhados, como é o caso do Rationale divinorum officiorum, do bispo Durand de Mende, escrito em 1286, que busca explicar o significado simbólico da liturgia e dos objetos que a envolvem (como as partes do edifício religioso, as imagens, as alfaias etc). Em seu primeiro capítulo há várias referências às imagens, o que fez com que já tenha sido comparado a um "manual" de iconografia. Nele podemos ler, por exemplo:

Devemos saber que existem três maneiras particularmente adequadas de pintar a imagem do Salvador em uma igreja: sentado em um trono, suspenso no suplício da cruz ou encolhido no colo de sua mãe. Porém, como João Batista apontou Cristo dizendo: 'Eis o cordeiro de Deus', alguns o pintam com as feições de um cordeiro. Contudo, como a obscuridade passou e Cristo se tornou, de fato, um homem, o papa Adriano disse que ele deve ser pintado na forma humana. O cordeiro de Deus não deve ser pintado na cruz como motivo principal, mas depois de pintar o homem nada impede que se pinte o cordeiro na parte inferior ou posterior, já que ele é o verdadeiro cordeiro que redime o mundo de seus pecados (DURAND DE MENDE, 1995, p. 37). 
Novamente estamos diante de uma preocupação que vai além de ditar normas: o bispo recomenda imagens adequadas e, mais ainda, justifica tais recomendações. Do ponto de vista da análise do texto, cabe notar como ele fornece também descrições, além de interpretações, o que só reforça a ressalva que fizemos inicialmente, a respeito da ausência de fronteiras rígidas entre os diferentes tipos de discurso.

\section{Dos discursos sobre a recepção}

O terceiro grupo é bem menos comum que os anteriores: trata-se daqueles discursos que dão conta, de alguma forma, da recepção das imagens. Eles são menos frequentes porque os discursos privilegiam as imagens, mais que os atores sociais envolvidos com elas - sejam eles seus consumidores (espectadores) ou mesmo, como veremos a seguir, seus produtores.

Mas é certo que há exceções, inclusive um dos textos mais conhecidos dos medievalistas a respeito de imagens, a carta de São Bernardo de Claraval ao abade Guilherme de Saint-Thierry entre 1122 e 1125, em que a recepção da obra pode ser percebida em dois níveis antagônicos, o da crítica e o do fascínio:

\footnotetext{
Mas nos capitéis dos claustros, onde os irmãos fazem sua leitura, que razão de ser têm tantos monstros ridículos, tanta beleza deforme e tanta deformidade artística? Esses macacos imundos, esses leões ferozes, esses horriveis centauros, essas representações e máscaras com corpos de animal e caras de homens, esses tigres com pintas, esses soldados combatendo, esses caçadores com cornos... Poderás também encontrar muitos corpos humanos pendurados de uma só cabeça e um só tronco para várias cabeças. Aqui um quadrúpede com cauda de serpente, lá um peixe com cabeça de quadrúpede, ou uma besta com peitilho de cavalo e seus quartos traseiros de cabra das montanhas. Ou aquele outro bicho com chifres na cabeça e forma de cavalo na outra metade do seu corpo. Por todas as partes aparece tão grande e prodigiosa variedade dos mais diversos caprichos que aos monges lhes agrada mais ler nos mármores do que nos códices e passar o dia todo admirando tanto detalhe sem meditar sobre a lei de Deus. Ai Deus meu! Já que nos fizemos insensíveis a tanta estupidez, como não nos dói tanto esbanjamento? (BERNARDVS CLARAEVALLENSIS, 1854, col. 915-916). ${ }^{8}$
}

${ }^{8}$ Tradução para o português de Selene Candian dos Santos. 
Lemos aí uma posição contemporânea e antagônica ao já mencionado discurso de Suger - o que mais uma vez contradiz a ideia de que a Idade Média seria um único bloco. A minuciosa e maravilhosa (no sentido medieval do termo, mirabilia) descrição do que poderiam ser esculturas em capitéis denota como elas afetam o abade cisterciense (o "envergonhar-se da loucura" poderia inclusive ser uma referência a si próprio). E que, em resposta, busca uma saída "prática", evocando os gastos que elas geram.

Há reações menos inflamadas, e que estão mais próximas da retórica pedagógico-normativa cristã - no sentido de indicarem o comportamento do fiel frente às imagens (e que não deve nunca ser de adoração). Novamente, o Oriente tem precedência, como pode ser lido em uma oração do bispo Gregório de Nissa, no século IV:

Eu vi muitas vezes a representação [rei imaginem in pictura] dessa paixão e nunca me vi sem lágrimas em face desse espetáculo, pois a arte da pintura [ars pingendi] coloca a narrativa sob nossos olhos de maneira evidente. Isaac está em frente de seu pai, ao lado do altar, com os joelhos flexionados e as mãos amarradas atrás das costas. Este apoia os pés sobre seus quadris e puxa para trás, com sua mão esquerda, os cabelos da criança. Ele se inclina de modo impiedoso em direção à criança que o olha, ergue com a mão direita a espada para degolá-lo; a ponta da espada já está quase tocando o corpo, quando lhe chega de Deus uma voz que impede o ato (GREGORIVS NYSSENVS, 1863, col. 571).

As lágrimas serão um topos, recomendadas para as imagens de devoção - não importa o quão frequentada elas sejam. E a compunção busca ser revivida por meio da ekphrasis, verdadeira imagem verbal, da qual falaremos mais adiante.

Outro exemplo é uma passagem da Vida de Santa Maura, atribuída a Prudêncio de Troyes, na metade do século IX:

Desde a mais tenra idade, ela ficava todos os dias, desde as laudas e as matinas até a hora sexta, na igreja dos apóstolos onde, como sabeis, a imagem do Salvador encontra-se pintada de três modos: de fato, ele é representado como menino sentado no colo de sua mãe, como grande senhor sentado no trono de majestade e como jovem rapaz suspenso na cruz. Desde a mais tenra idade, Santa Maura não perdia o hábito de fazer cada dia tudo o que foi dito antes, e prosternar todo seu 
corpo, primeiramente diante do menino, em segundo lugar diante do jovem rapaz e em terceiro lugar diante do rei (PRUDENTIVS TRECENSIS, 1862, col. 1372).

Vemos nesse fragmento não só o comportamento piedoso e decoroso recomendado frente às imagens, apresentadas e descritas hierarquicamente (SCHMITT (2007, p. 177-182), como os mesmos três tipos de representação do Cristo que seriam retomados por Durand de Mende alguns séculos depois - o que mostra a força dos modelos iconográficos, ainda quando não são normas e leis.

Um outro conjunto de textos trata de uma forma específica de relação entre o espectador-fiel e as imagens: a recepção milagrosa, por assim dizer. São passagens de obras hagiográficas em que as imagens operam milagres, falam, abraçam, em suma, de certa forma ultrapassam a barreira da objetualidade e se comportam como os protótipos que representam.

Uma compilação de exemplos dessa atuação milagrosa pode ser encontrada no Liber miraculorum sanctae Fidis, escrito pelo clérigo Bernard de Angers no início do século $\mathrm{XI}$, em que ele descreve os milagres de Santa Fé e, o que nos interessa mais aqui, sua primeira reação - negativa - à imagem, antes de sua "conversão".

Após o terceiro dia finalmente chegamos a Conques. Quando entramos no mosteiro, o destino fez, por acaso, com que o lugar reservado, onde a imagem venerada é preservada, estivesse aberto. Ficamos nas proximidades, mas por causa da multidão a seus pés, tínhamos um espaço tão restrito que não éramos capazes de seguir em frente. Embora agora seja doloroso para mim que eu tenha feito uma coisa dessas, fiquei olhando para a imagem e fiz a seguinte oração: 'Santa Fé, cujo corpo em parte repousa nesta semelhança, ajude-me no dia do Juízo Final'. E, com um sorriso de soslaio, olhei para Bernier, meu companheiro erudito, pensando que era um absurdo, claro, e muito além dos limites da razão que tantos seres racionais se ajoelhassem diante de uma coisa muda e insensata. Em verdade, meu discurso vazio e minha ignorância por então não advinham de um bom coração. E isso porque a santa imagem é buscada não como um ídolo que exige sacrifícios, mas porque ela comemora uma mártir. Já que a reverência a ela honra a Deus nas alturas, era desprezível de minha parte comparar sua estátua a estátuas de Vênus ou Diana. Mais tarde eu ficaria muito triste de ter agido de forma tão tola com uma santa de Deus (BERNARDVS ANDEGAVENSIS, 1897, p. 47-48).

Após a santa lhe aparecer em sonho, o religioso se arrepende de suas restrições iniciais e suas burlas à imagem e compila, então, os milagres que ela fez: desde se mover a castigar quem duvidava dela e a pedir ouro e joias para aumentar sua ornamentação. É interessante observar a diferença que existiria, em 
princípio, entre os diferentes tipos de espectadores: um clérigo educado e camponeses. Seguindo o modelo gregoriano, a imagem seria destinada aos últimos - mais precisamente: a imagem pintada, e não a tridimensional. Na prática, porém, o uso de imagens tridimensionais para culto já se desenvolvera, e a passagem do milênio marcava uma mudança importante na difusão desse culto: também junto à hierarquia da Igreja. (SCHMITT, 2007, p. 138-143).

Mas um dos casos mais conhecidos de interação entre a imagem e o espectador, e que se torna um paradigma a partir daí, é o encontro de São Francisco com o crucifixo de San Damião, na narrativa de Celano:

\footnotetext{
Levado pelo Espírito, entrou para rezar e se ajoelhou devotamente. Tocado por uma sensação que era nova para ele, sentiu-se diferente do que tinha entrado. Pouco depois, coisa inaudita: a imagem do Crucificado mexeu os lábios e falou com ele: 'Francisco, vai e repara minha casa que, como vês, está toda destruída'"(TOMÁS DE CELANO, 1983, p. 294).
}

No início da passagem, encontramos novamente menção à "etiqueta" corporal frente à imagem prosternação e súplicas, que se somam às lágrimas e às velas acesas. Mas não só isso: a imagem responde a essa resposta do espectador. Temos aí a recepção da recepção, algo que mostra o poder que as imagens alcançaram no mundo cristão, para muito além das restrições iniciais.

\section{Dos discursos sobre os artistas}

No quarto grupo, sobre os produtores de imagens, encontramos textos bastante diversos, desde os mais objetivos, como recomendações para artistas, contratos, receitas, testamentos, até aqueles que tecem comentários sobre a qualidade desses artistas.

As instruções para os artistas não são muito comuns de serem encontradas. Por um lado, há a obviedade do fato de que muitas deveriam ser feitas oralmente, e isso de fato é narrado em uma passagem da História dos Francos, de Gregório de Tours, em que ele diz que a esposa do bispo de Clermont, Namatius, que construiu a igreja de Santo Estêvão, lia para os pintores "a história dos feitos dos velhos tempos e apontava para os pintores que temas deveriam ser representados nas paredes" (GRÉGOIRE DE TOURS, 2005, p. 106). 
Devemos lembrar, também, que, pelo menos no caso das miniaturas, elas podiam ser apagadas pela obra concluída. Podem ficar perceptíveis apenas quando a obra ficou inconclusa, como em um manuscrito da Peregrinação da vida humana, de Guillaume de Deguileville, de 1393, que tem em uma de suas margens a indicação: "Remiet ne faites rien cy, car je ferai une figure qui doit y estre" ("Remiet, não faça nada aqui, porque eu farei uma imagem que deve estar aqui"), ao lado de um espaço que permaneceu em branco (BNF Fr 823, fol. 18v). Ou então por ter sido danificada, como no caso da Itala de Quedlinburg (Berlim, Staatsbibliothek Preussischer Kulturbesitz, Cod. theol. lat. fol. 485), manuscrito produzido em Roma por volta do segundo quarto do século $V$ e do qual só restam quatro páginas: parte da iluminação se desprendeu do pergaminho, deixando ver as inscrições que ficariam cobertas pelos pigmentos. Trata-se de instruções breves, mas com espaço para a intervenção do artista, como nesse exemplo, no fólio 2 r:

[...] Faça o profeta em um carro, conversando contra o rei, Saul sacrificando e dois dos servos do rei.

Faça onde o profeta se retira e o rei Saul tenta segurá-lo pela ponta de seu manto, corta-a e se retira correndo (DEGERING; BOECKLER 1932, p. 67).

Quanto aos contratos propriamente ditos, poucos são os anteriores ao século XIII que chegaram até nós - o que não significa que não existissem, pois além da fragilidade dos documentos, muitos poderiam também ter sido feitos oralmente. Dentre os vários contratos do final da Idade Média que foram preservados, escolhemos um, de 1402, de um prebendado de Santa Maria de Copons com o pintor valenciano Lluis Borrassá para a pintura de um grande retábulo. Nele é estipulado o prazo (seis meses), o tipo de pagamento especificado e em quantas vezes será feito, e são fornecidos detalhes a respeito dos materiais e das técnicas. Citamos somente um excerto desse longo documento:

\footnotetext{
Item, se recorde que esta obra se fará com o melhor ouro de florins florentinos [...] se entende, assim, que o manto da Virgem será de um fino azul de Acre, e algumas imagens também serão pintadas com o citado azul. A camada superior se fará com boas e finas pinturas, incluindo um belo carmim [...] de acordo com o costume em outros belos retábulos. (BINSKI, 2000, p. 52).
}

Os testamentos são mais comuns no final da Idade Média, e além daqueles de nobres e ricos burgueses legando seus bens, incluindo obras de arte, de grande interesse são também os dos próprios artistas, como o de Hugh, "peyntour" de San Alban, que trabalhara inclusive para o rei Eduardo III da Inglaterra, de 1361: 
Deixo a casa em que vivo à minha mulher Agnès. [...] Desejo, também, que todo meu equipamento com diferentes pinturas necessárias à minha arte seja vendido e 0 dinheiro arrecadado seja distribuído aos pobres para salvação da minha alma. [...]

Deixo também a Agnès, minha esposa, para sua manutenção e a de meus filhos uma tábua [retábulo] lombarda de seis peças que me custou 20 libras quando estava ainda sem terminar e sem moldura, além de outros objetos. [...] (BINSKI, 2000, p. 12-13).

Ele doou ainda dinheiro a várias confrarias, ajudantes, peregrinos, eremitas, além de uma cruz processional de prata. O retábulo seria talvez para aprender ofício - o que era provável quando se sabe que seu ateliê era especialista em pintura italiana (embora ele não mencione nada a respeito de devoção).

Quanto aos comentários sobre os artistas, trata-se em geral de trechos breves, em necrológios, crônicas e hagiografias, normalmente com tom laudatório, como convém a essas peças epidíticas. Assim, por exemplo, a Gesta dos abades de Saint Albans, do século XIV, redigida por Thomas Walsingham, retoma a descrição que fez Mateus Paris de Walter de Colchester, ourives, pintor e escultor, e que fôra, como ele, monge em Saint Albans no século XIII: "um artista sem igual em todos os tipos de artes, e não creio que ninguém possa igualá-lo no futuro" (WALSINGHAM, 1869, p. 280).

Existem casos em que os textos laudatórios - ou pelo menos inscrições atribuindo a autoria - podem ser encontrados nas próprias imagens. Os exemplos não são poucos, embora em sua maioria sejam formulares, como "OTHELRIC ME FECIT", na igreja sueca de Husaby de meados do século XII. Não existe certeza de que se trata do artista, poderia também ser o comitente ${ }^{9}$. Mas, em suma, a imagem aponta aquele que "a fez". Um pouco menos comuns são aqueles em que há um texto mais elaborado, como na fachada da catedral de Módena, do final do século XI, onde se pode ler em uma cartela portada por Enoc e Elias: "INTER SCVLTORES OVANTO SIS DIGNVS ONORE CLARET SCVLTVRA NVNC WILIGELMO TVA" ("Tua escultura, Wiligelmus, mostra hoje como tu és digno de honra entre os escultores").

Por vezes, esse elogio pode ser intenso ao ponto de comparar os artistas a seres mais que humanos: assim, por exemplo, na Espanha do século XI se difundiu uma lenda de que a prestigiosa "Cruz de los ángeles", encomendada por Alfonso II em 808, teria sido confeccionada por anjos vestidos de peregrinos, que desapareceram sem vestígios após a obra concluída, deixando suas vestes no ateliê (CID PRIEGO, 1994, p. 731 $)^{10}$. Ou então, que os artistas teriam tido ajudantes mais que especiais, como é caso contado na Crônica

\footnotetext{
9 Ver, a esse respeito, entre outros, Pereira (2012, p. 103-111).

${ }^{10} \mathrm{~A}$ primeira versão, mais breve, aparece em um manuscrito do século XI (Bibliothèque Municipale de Valenciennes, MS. 99, fol. 1v) e diz: "crux ibi monstratur opere angelico fabricata" (FERNANDEZ CONDE, 1972, p. 160). O historiador da arte francês Jacques Fontaine se preocupa, logo após mencionar também a lenda, em sugerir uma explicação histórica: os tais anjos nada mais seriam que ourives vindos do outro lado dos Pirineus ou do Norte da Itália, ou mais provavelmente ourives "emprestados" por Carlos Magno ao rei Alfonso II (FONTAINE, 1978, p. 372).
} 
do mosteiro de Saint Gall, do século XI: a Virgem teria sido vista ajudando (passando os instrumentos) e ensinando o artista Tuotilo a cinzelar uma imagem sua (MARIAUX, 2001, p. 174) ${ }^{11}$.

\title{
Dos discursos descritivos
}

No quinto e último grupo, encontramos os textos mais descritivos, referindo-se tanto ao conteúdo iconográfico quanto à materialidade das imagens - e que são, de longe, os mais comuns. Nestes últimos, mais do que o trabalho do artista, em geral era o custo, a raridade e os efeitos estéticos (sobretudo o brilho) de uma imagem que eram prezados - e, nesse sentido, o ouro mais do que qualquer outra matéria prima.

O abade Suger é, novamente, um guia precioso, pois da mesma forma que não economizou recursos na reforma de Saint Denis, tampouco economizou palavras para descrever seus feitos na ornamentação da igreja. Um exemplo é sua descrição do painel de ouro do altar no coro superior:

\begin{abstract}
Nesse painel, que fica diante do mais sagrado corpo, calculamos haver posto cerca de 42 marcos de ouro; uma profusão de pedras preciosas, zircões, rubis, safiras, esmeraldas e topázios, e inclusive uma fileira de pérolas de diferentes tamanhos, em uma quantidade que não havíamos previsto. Deveríeis ter visto reis e príncipes e numerosas personalidades famosas tirando os anéis dos dedos e pedindo que o ouro dos anéis e as pedras preciosas e as joias, pelo aro dos Santos Mártires, fossem incrustados naquele painel. Arcebispos e bispos não ficavam atrás, tiravam ali até mesmo os anéis de consagração, com grande devoção, e os ofereciam a Deus e seus santos. Também chegavam a nós de diferentes reinos e nações um número tão grande de vendedores de gemas, que não alcançávamos comprar tanto quanto nos ofereciam para vender, contribuindo todos com os gastos (SUGER, 1979, p. 54-55).
\end{abstract}

Trata-se de uma forma particular de ekphrasis: ainda que esse gênero da retórica clássica fosse o modo de descrever coisas (sobretudo imagens) ausentes como se elas estivessem presentes, e sobretudo em seu conteúdo iconográfico, aqui a ênfase está na materialidade.

\footnotetext{
${ }^{11}$ No entanto, o autor da Crônica se refere também a uma inscrição que teria aparecido sobre a obra após a partida do artista informando que ela teria sido cinzelada pela própria Virgem ("Hoc panthema pia celaverat ipsa Maria").
} 
Encontramos exemplos mais tradicionais, como a descrição da porta meridional (Puerta de las Platerías ou de los Orfebres) da catedral de Santiago de Compostela no capítulo 5 do Codex Calixtinus, que teria sido escrito entre 1135 e 1140 pelo francês Aimery Picaud:

O portal meridional da basílica apostólica compreende, como dissemos, duas portas e quatro folhas. Na porta da direita, externamente, foi esculpida no primeiro registro sobre a porta a Traição do Cristo, realizada de maneira notável. Aqui, Nosso Senhor está atado à coluna pela mão dos judeus; acolá, é flagelado; ali, Pilatos, sentado em seu tribunal como para julgá-lo. Acima, em outro registro, a bemaventurada Maria, Mãe do Senhor, está representada com seu filho em Belém; também estão os três reis que vêm visitar o menino e sua mãe, oferecendo-lhes o triplo presente. Ademais, aparecem a estrela e o anjo que lhes adverte a não regressar até Herodes.

[...] [na porta da esquerda] no primeiro registro sobre a entrada, está esculpida a Tentação de Nosso Senhor; em frente ao Cristo há horrorosos anjos parecidos com monstros que se instalam sobre o teto do templo; outros the apresentam pedras convidando-o a transformá-las em pão; outros lhe mostram os reinos desse mundo, fingindo querer dá-los a ele se, caindo de joelhos frente a eles, os adorasse - o que Deus não quer. Mas outros anjos puros, bons anjos, uns atrás e outros acima, vêm incensá-lo e servir-lhe.

[...] Não há que se esquecer de mencionar a mulher que se encontra ao lado da Tentação do Cristo: tem entre suas mãos a cabeça imunda de seu sedutor que foi arrancada por seu próprio marido e que deve beijar duas vezes por dia, por ordem dele. Que terrível e admirável castigo da mulher adúltera, que é necessário ser contado a todos! (LIBER..., 1951, p. 560-562)

Nesse longo exemplo, além da preocupação iconográfica, que faz com que as cenas e as personagens sejam identificadas, há também algo muito comum à ekphrasis medieval: a necessidade de incluir uma interpretação - em geral, de tipo moralizante, como fica bastante claro aqui na descrição da mulher. Nada na imagem permite sua identificação como uma mulher adúltera (ainda que isso pudesse advir de uma tradição oral), mas a força do modelo Eva-Madalena está aí patente ${ }^{12}$.

Outro exemplo em que essa dimensão interpretativa da descrição é bastante explícita se encontra no chamado Breviário de Belleville, um breviário dominicano iluminado por Jean Pucelle e seu ateliêê,

${ }_{12}$ Para Serafin Moralejo (1992, p. 217-218), seria uma Madalena penitente precoce.

${ }^{13}$ Seu nome aparece em notas marginais registrando pagamentos a outros iluminadores. Ver a esse respeito Morand (1962, p. 3133). 
provavelmente entre 1323 e 1326 (BNF lat 10483-10484). No primeiro volume, podemos ler logo em sua abertura a frase, rubricada, que deu origem ao título deste artigo: "L'exposition des ymages des figures qui sunt $u$ kalendrier et $u$ sautier, et est proprement l'acordance du veil testament et du nouvel" (fólio $2 \mathrm{r}$ ). $\mathrm{O}$ autor ${ }^{14}$ anuncia o seu próprio trabalho de exegese figurativa, que explicará em maiores detalhes na sequência. Mas é digno de nota perceber a duplicação do termo que em princípio poderíamos traduzir apenas por imagem: ymage e figure. Lucy F. Sandler (1984, p. 74) traduz a expressão para o inglês como "figural images", mas isso reduz a importância dos termos que são escritos explicitamente separados. A distinção não é casual, as figures têm um sentido mais exegético, teórico (como se diz que do Antigo Testamento, que ele prefigura o Novo (AUERBACH, 1997, p. 26-51), enquanto ymages seriam a representação plástica destas. Ou seja, o autor vai expor as "imagens das figuras" que estão no calendário e no saltério, ou seja, a concordância do Antigo e do Novo Testamento, como se segue:

São Gregório diz que aquele que vê e não compreende obtém tanto proveito quanto aquele que vai à caça e não traz nada; com isto está de acordo o sábio Salomão, quando diz que, escutando e compreendendo se adquire sabedoria e quando se vê algo que está apresentado de forma obscura, se deve buscar e averiguar o sentido e a explicação; é por isso que nos fólios que se seguem até o final do Saltério há algumas figuras [figures] não demasiado claras, e quero explicá-las, para que todos possam entendê-las e delas tirar proveito.

A Escritura diz que o Deus não é um homem que pode se equivocar ou mudar, porque ainda que o homem e todas as criaturas possam mudar em si, em suas obras e em seus pensamentos, sem dúvida, o Criador, artífice supremo, não pode sofrer mutações. Como ele mesmo ordenou e estabeleceu o Antigo e o Novo Testamento, convém que ambos sejam postos de acordo e expressem uma unidade. Estão de acordo com isso os Santos em muitas passagens da Sagrada Escritura, que dizem que o Novo Testamento está todo figurado e dado em figuras no Antigo [le nouvel testament est tout figure et baillie en figures en lancien].

E essa concordância indicam as imagens que estão aqui depois [et cete acordance senefient les ymages qui sunt cy apres].

Os Apóstolos são os executores do Novo Testamento, são os que tomam os versículos obscuros do Antigo Testamento e os transformam em artigos da fé; assim é que em cada um dos doze meses está um dos doze apóstolos e um dos doze profetas, de maneira que o Profeta apresenta ao Apóstolo uma profecia oculta e o Apóstolo a esclarece e converte em dogma. Por isso, da Sinagoga, que foi no tempo do Antigo Testamento, e da Igreja, que está no tempo do Novo, falamos de duas

${ }_{14}$ Estamos usando o termo autor em um sentido bastante amplo. Não se sabe quem elaborou a obra, mas sabe-se que foi toda escrita por uma só mão (SANDLER, 1984, p. 74). 
maneiras diferentes, em um sentido grosseiro e material e em um sentido sutil e espiritual. Eu explico um e outro sentido: com efeito, detrás de cada um há uma sinagoga material da qual o Profeta tira uma pedra que apresenta ao Apóstolo com a profecia. A Sinagoga aparece cada vez mais arruinada, como se pode ver nas figuras que se seguem adiante [selonc ce que il vont plus avant]. E os artigos da fé se multiplicam, como você pode ver nas figuras [comme vous poes veoir es figures] [...] (BNF Lat 10483, fol. 2r-2v).

Em princípio, nesse trecho fica clara essa distinção: as ymages são o que vai se seguir mais adiante (como diz no fólio 2r). E quando o autor está explicando seu método de exegese tipológica, usa figures. No entanto, na última frase (já no fólio 2v), permanece certa ambiguidade. O verbo "ver" e a ideia de apresentação indicariam que se estaria falando de imagens plásticas, mas o termo usado é "figures". Essa variação não é incomum nos textos medievais, e ela reforça a imbricação entre essas duas construções imagéticas.

Outro exemplo da explanação das imagens e de seu modo de interpretação pode ser visto em um romance de cavalaria do século XIII, a Morte do rei Arthur:

Naquele dia o tempo estava lindo, o sol se tinha levantado em toda sua glória e os seus raios inundavam o quarto de todos os lados, de modo que ele recebia uma grande claridade. [...] Aconteceu de o rei começar a olhar ao redor, e perceber as imagens pintadas por Lancelote durante o tempo que ele ali permanecera preso. $\mathrm{O}$ rei Artur era suficientemente educado para poder entender o significado de uma escrita. Quando viu as letras traçadas nas pinturas, que davam seu sentido, ele começou a decifrá-los; ele não demorou a perceber claramente que a sala estava decorada com os altos feitos de Lancelote e as proezas que ele tinha realizado quando era um jovem cavaleiro. [...]

Assim, o rei começou a tomar conhecimento das atividades de Lancelote através das representações que ele via. [...] (OLLIER, 1992, p. 99-100).

Nesta passagem, a imagem informa, mas ela só o faz porque teve a escrita como intermediária. Como no já mencionado exemplo de Gregório de Nissa, a ideia de que a imagem serve somente de instrumento didático é limitadora - por mais que o modelo gregoriano seja atraente, porque se encaixa bem com a ideia que do Renascimento em diante se fez da Idade Média, como um período de primitivo, infantil. Tal concepção corresponde, por exemplo, à ideia que temos modernamente sobre livros: quando feitos para crianças ainda não alfabetizadas, são unicamente compostos por imagens. À medida que vão crescendo, 
eles vão sendo povoados por palavras, depois frases, depois páginas inteiras de textos, até que elas desaparecem, na imensa maioria de livros para "adultos". Ora, nada mais anacrônico, negativamente anacrônico em relação à Idade Média. Da mesma forma que não se pode estudar as imagens medievais sem estudar os textos medievais que delas tratavam, tampouco se pode querer enxergar neles toda a "verdade" e a autoridade sobre elas.

Se retomarmos nossa narrativa do início do texto, temos que admitir que, quando o historiador faz da imagem um novo verbo, há algo de inexorável nessa operação, uma vez que seu instrumento de trabalho é também o verbo. $O$ problema reside em achar que tal operação se resume nisso; em fazer desaparecer a imagem sob camadas de texto; em parar o trabalho aí. Há, ao contrário, que dialetizar, passar do texto à imagem e vice-versa. Afinal, como já dizia Foucault (1967, p. 49-50), "o discurso e a figura têm, cada um, seu modo de ser; mas eles mantêm entre si relações complexas e embaralhadas. É seu funcionamento recíproco que se trata de descrever".

\section{Referências}

AUERBACH, Erich. Figura. In: Figura. Tradução de Duda Machado. São Paulo: Ática, 1997. p. 13-64.

BERNARDVS ANDEGAVENSIS. Liber miraculorum Sancta Fidis. Paris: A. Picard, 1897.

BERNARDVS CLARAEVALLENSIS. Apologia ad guillelmum sancti theoderici abbatem. Paris: Migne, 1854.

BINSKI, P. Pintores. Madrid: Akal, 2000.

BLUM, P. Z.; CROSBY, S. M. Le portail central de la façade occidentale de Saint-Denis. Bulletin Monumental, Paris, v. 131, n. 3, p. 209-266, 1973.

BRÉVIAIRE de Belleville. Paris: Biblliothèque Nationale de France, MS. Lat 10483.

CHAZELLE, C. Pictures, books and the illiterate: Pope Gregory I's letters to serenus of marseille. Word and Image, London, n. 6, p. 138-153, 1990.

CID PRIEGO, C. Inventario iconográfico medieval de la Cruz de los Ángeles de la Cámara Santa de la Catedral de Oviedo. Anales de la Historia del Arte, Madrid, n. 4, p. 731-746, 1994.

CLEMENTE DE ALEXANDRÍA. El pedagogo. Tradução de Marcelo Merino e Emilio Redondo. Madrid: Ciudad Nueva, 2009. (Fuentes Patrísticas, 5). 
DEGERING, H.; BOECKLER, A. Die quedlinburger itala fragmente. Berlim: Cassiodor Gesellschaft, 1932.

DUGGAN, L. "Was art really the 'book of illiterate'?". Word and Image, London, v. 5, p. 227-251, 1989.

DURAND DE MENDE. Rationale divinorum officiorum. Turnhout: Brepols, 1995. (Corpus Christianorum. Continuatio Medievalis, 140).

FERNANDEZ CONDE, F. J. La iglesia de asturias en la alta edad media. Oviedo: Instituto de Estudios Asturianos, 1972.

FONTAINE, J. El prerromanico. Madrid: Encuentro, 1978.

FOUCAULT, M. Les mots et les images. Le Nouvel Observateur, Paris, n. 154, p. 49-50, out. 1967.

GERSON, P. L. Suger as iconographer: the central portal of the west façade of Saint Denis. In: . Abbot suger and saint-denis: a symposium. New York: The Metropolitan Museum of Art, 1986. p. 183-198.

GRÉGOIRE DE TOURS. Histoire des francs. Tradução de Robert Latouche. Paris: Les Belles Lettres, 2005.

GREGORIVS MAGNVS. Registri epistolarum. Paris: Migne, 1895. (Patrologia Latina 77).

GREGORIVS NYSSENVS. De deitate filii et spiritus sancti. Paris: Migne, 1863 (Patrologia Graeca, 46).

HORACE. Satires, epistles and ars poetica. London: Harvard University Press, 1926. (Loeb Classical Library, 194).

HOROS du Concile de Nicée II. Tradução de M. F. Auzépy. In: BOESPFLUG, F.; LOSSKY, N. (Ed.). Nicée II, 787-1987: douze siècles d'images religieuses. Paris: Cerf, 1987. p. 31-35.

LIBER Sancti Jacobi. Codex calixtinus. Tradução de S. Moralejo, C. Torres e J. Feo. Santiago de Compostela: CSIC, 1951.

MÂLE, É. L'art religieux au XIIle siècle en France. 3. ed. Paris: Armand Colin, 1910.

MARIAUX, P. A. La Vierge dans l'atelier de Tuotilo. De l'artiste médiéval considéré comme un 'théodidacte'. Revue de l'Histoire des Religions, Paris, v. 218, n. 2, p. 171-193, 2001.

MORALEJO, S. The codex calixtinus as an art historical source. In: WILLIAMS, J; STONES, A. (Ed.). The codex calixtinus and the shrine of St. James. Tübingen: Gunter Narr, 1992. p. 207-228.

MORAND, K. Jean Pucelle. Oxford: Clarendon Press, 1962.

OLLIER, Marie-Louise (Ed.). La Mort du Roi Arthur. Paris: UGE, 1992. 
PAULIN OF NOLA. The poems. Tradução de P. G. Walsh. New York: Newman, 1975. (Ancient Christian Writers, 40).

PEREIRA, M. C. C. L. Sobre criação e autoria: as 'assinaturas' epigráficas no Ocidente medieval. In: OLIVEIRA, T. (Org.). Conhecimento e educação no medievo. São Luís: Eduema, 2012. p. 103-111.

PLATÃO. República. Tradução de Maria Helena da Rocha Pereira. 9. ed. Lisboa: Calouste Gulbenkian, 2001.

PRUDENTIVS TRECENSIS. Sermo de vita et morte gloriosae virginis Maurae. Paris: Migne, 1862. (Patrologia Latina, 115).

SANDLER, L. F. Jean Pucelle and the lost miniatures of the belleville breviary. The Art Bulletin, New York, v. 66, n. 1, p. $73-96,1984$.

SANTO AGOSTINHO. Solilóquios e a vida feliz. Tradução de Adaury Fiorotti. São Paulo: Paulus, 1998.

SCHMITT, J. C. O corpo das imagens: ensaios sobre a cultura visual na Idade Média. Tradução de José Rivair Macedo. Bauru: EDUSC, 2007.

SUGER. De administratione. Tradução de Erwin Panofsky. In: PANOFSKY, E. Abbot suger on the abbey church of Saint-Denis and its art treasures. 2. ed. Princeton: Princeton University Press, 1979. p. 40-81.

TOMÁS DE CELANO. Vida II. Tradução para o português de Fr. José Carlos Pedroso. In: SILVEIRA, F. I.; REIS, O. (Ed.). Escritos e biografias de São Francisco de Assis. Petrópolis: Vozes, 1983. p. 286-446.

WALSINGHAM, T. Gesta abbatum monasterii Sancti Albani. Londres: Longmans, Green, Reader and Dyer, 1869. 3 v.

Recebido em 20/04/2016 - Aprovado em 11/06/2016. 